\title{
Intérêt de la culture associée légumineuses-maïs et stratégie de résilience face à la disponibilité en terre cultivable : le cas de la ferme agricole de Kafigué dans département de Korhogo (Nord de la Côte d'Ivoire)
}

\author{
Kouakou Konan Elie \\ Doctorant, Université Félix Houphouët-Boigny, UFR des Sciences de la \\ Terre et des Ressources Minières, Département des Sciences du Sol \\ Akotto Odi Faustin \\ Enseignant-Chercheur, Université Félix Houphouët-Boigny, UFR des \\ Sciences de la Terre et des Ressources Minières, Filière Pédologie et \\ Agriculture Durable, Côte d'Ivoire \\ N'Guessan Kouamé Antoine \\ Enseignant-chercheur, UFR des Sciences Biologiques, \\ Université Peleforo Gon Coulibaly de Korhogo) \\ Yao-Kouamé Albert, (Université Félix Houphouët-Boigny Abidjan-Cocody, \\ UFR des Sciences de la Terre et des Ressources Minières, Département des \\ Sciences du Sol)
}

Doi:10.19044/esj.2021.v17n17p318

Submitted: 06 April 2021

Accepted: 11 May 2021

Published: 31 May 2021
Copyright 2021 Author(s)

Under Creative Commons BY-NC-ND

4.0 OPEN ACCESS

Cite As:

Elie K.K., Faustin A.O. \& Antoine N.K. (2021). Intérêt de la culture associée légumineusesmaïs et stratégie de résilience face à la disponibilité en terre cultivable : le cas de la ferme agricole de Kafigué dans département de Korhogo (Nord de la Côte d'Ivoire). European Scientific Journal, ESJ, 17(17), 318. https://doi.org/10.19044/esj.2021.v17n17p318

\section{Résumé}

En raison de la relative disparition progressive des jachères qui permettaient auparavant la conservation des ressources minérales du sol, la problématique de recherche agronomique dans le Nord de la Côte d'Ivoire est étroitement liée à la petite superficie des exploitations agricoles. Dans un tel contexte, la méthode a consisté à caractériser deux facteurs déterminants : le caractère «terre » qui représente la ressource rare des exploitations agricoles et le caractère "légumineuse » dont la nécessité d'insertion dans les associations. Des systèmes de cultures pures, les cultures associées maïs- 
cajanus et maïs-arachide ont été étudiés dans le Nord-Côte d'Ivoire. Les résultats ont montré que l'arrangement spatial du semis modifie sensiblement la production de ces associations. On constate que la culture est favorisée par l'association céréale-légumineuse par rapport à la culture pure. Sur le sol objet du présent travail, le maïs associé valorise aussi bien la productivité que le maïs cultivé individuellement. Les possibilités d'améliorer l'association traditionnelle maïs-légumineuse, sans application des fertilisants, sont également examinées. La supériorité de l'association réside plutôt dans la valorisation du capital terre (Land Equivalent Ratio, LER >1) que dans la productivité du travail, qui ne se distingue pas globalement de celle des cultures pures ; cela signifierait que l'association gagne de son intérêt en milieu dégradé. Les différents LER totaux calculés montrent également une différence non significative entre les rendements obtenus sur Labours à plat et billons dans toutes les différentes associations légumineuses-maïs. De ce fait, les paysans n'ont aucune crainte à cultiver sur le labour à plat pour éviter de créer des poches à l'érosion à travers des sillons créés par le billonnage et qui se transforment en rigoles. Les meilleurs systèmes d'associations sont cajanusmaïs et cajanus-maïs-arachide.

Mots clés : Cultures associées, maïs, arachide, cajanus, LER, Côte d'Ivoire 


\title{
Importance of the Intercropping Leguminous-Maïs, Strategy of Resilience to the Availability of Cultivable Land: Case of Kafigué Agricultural Farm in the Department Korhogo (Northern of Côte d'Ivoire)
}

\author{
Kouakou Konan Elie \\ Doctorant, Université Félix Houphouët-Boigny, UFR des Sciences de la \\ Terre et des Ressources Minières, Département des Sciences du Sol \\ Akotto Odi Faustin \\ Enseignant-Chercheur, Université Félix Houphouët-Boigny, UFR des \\ Sciences de la Terre et des Ressources Minières, Filière Pédologie et \\ Agriculture Durable, Côte d'Ivoire \\ N'Guessan Kouamé Antoine \\ Enseignant-chercheur, UFR des Sciences Biologiques, \\ Université Peleforo Gon Coulibaly de Korhogo) \\ Yao-Kouamé Albert, (Université Félix Houphouët-Boigny Abidjan-Cocody, \\ UFR des Sciences de la Terre et des Ressources Minières, Département des \\ Sciences du Sol)
}

\begin{abstract}
For the reason of the relative progressive disappearance of the fallow which allowed before the conservation of the soil mineral resources, the problems of agronomic research in the North of the Côte d'Ivoire are closely related to the small surface of the farms. In such a context, the method consisted in characterizing two determining factors: character "soil" which represents the rare resource of the farms and character "leguminous plant" of which need for insertion in intercropping systems. Farming systems pure, associated crop maize-cajanus and maize-groundnut were studied in the North of Côte d'Ivoire. The results showed that the spatial arrangement of sowing appreciably modifies the production of these intercropping systems. It is noted that the crop is supported by intercrop cereal-leguminous plant compared to the mixed crops. On soil, object of this work, the intercrop maize develops as well the productivity as individually cultivated maize. The possibilities of improving traditional intercrop maize-leguminous plants, without the application of fertilizers, are also examined. The superiority of intercropping lies rather in the valorization of the capital soil (Land Equivalent Ratio, LER $>1$ ) that in the labour productivity, which is not distinguished overall from that of the pure cultures; that would mean that intercropping gains of its interest in degraded area. The different calculated total LER also shows a non significant difference between the yields obtained on Labor flat and balks in
\end{abstract}


all various intercrop leguminous plant-maize. So the farmers don't have any fear to cultivate on the labor flat to avoid erosion through furrows created by the Balk and which are transformed into drains. The best intercropping systems are cajanus-maize and cajanus-maize-groundnut.

Keywords: Intercropping, maize, leguminous, yield, LER, Côte d'Ivoire

\section{Introduction}

Dans le nord du pays, il y a une saison des pluies par an, ce qui contraint les paysans à un seul cycle de culture. De plus, La seule stratégie adoptée par les paysans pour faire face à la baisse de la fertilité des sols, est l'apport systématique des engrais chimiques qui reste chers et pas toujours accessibles. Cette situation oblige les paysans à cultiver les céréales (maïs et sorgho) dans un système de culture en rotation avec le coton pour permettre aux céréales de bénéficier des arrières effets des engrais apportés à culture précédente de coton. Les agriculteurs pratiquent l'élevage de bovin et la culture attelée est généralisée. Ils ne pratiquent plus la jachère (Koulibaly et al., 2010, N'Guessan et al., 2019) car il n'y a plus de terres disponibles du fait de la forte densité de population rurale. Dans le contexte de croissance démographique actuelle et avec les effets du changement climatique, il est question que les agriculteurs développent des stratégies de résilience face à la pauvreté et à l'insécurité alimentaire (Akotto et al., 2020). L'intensification de la production par hectare est donc nécessaire.

Mais, les contraintes sont diverses : (i) les semis se font de façon aléatoire du faite de la non maitrise des saisons pluvieuses dues aux variabilités climatiques où il y a régulièrement des poches de sécheresse, (ii) une compétition entre usages de la biomasse végétale : les éleveurs transhumants ou semi-sédentaires pour la pâture de leurs animaux, les femmes pour le combustible pour la cuisine, les agriculteurs pour la production de fumier et l'alimentation du bétail, (iii) le prélèvement rapide des résidus au sol favorise l'érosion éolienne et hydrique lors des premières pluies. Ces contraintes expliquent que les agriculteurs sont demandeurs d'engrais minéraux pour cultiver des céréales. Ils sont également bien conscients de l'intérêt d'utiliser les résidus de culture pour maintenir la fertilité des sols par l'enfouissement ou pour la fabrication de fumure organique. Mais, les apports de fumure organique demeurent seulement concentrés autour des concessions.

Il est urgent de maximiser l'utilisation des terres pour accélérer les gains de productivité et promouvoir une réduction rapide du déficit de sécurité alimentaire attendu (Salama et Zeid, 2016). Dans ce contexte, les propositions pour l'amélioration des systèmes de culture pluviaux à base de céréales dans la région des savanes se multiplient. Cela peut nécessiter la mise en œuvre de différentes innovations parmi lesquelles la culture associée ou dérobée 
(Bedoussac et al., 2013) dans les céréales (céréale + arachide ; céréale + Cajanus cajan). Il s'agit aussi d'amener l'agriculteur à évaluer la quantité des différents fourrages dont il aura besoin tout au long de l'année et la quantité de fumures organiques qu'il pourrait produire chaque année (Scopel et al., 2005, Lal et al., 2007).

À l'instar de la majorité des horizons de surface des sols ferrugineux et ferrallitiques d'Afrique de l'Ouest, ceux de Korhogo (Nord de la Côte d'Ivoire) étaient considérés comme épuisés, totalement dégradés (Feller, 1994 et 1995), inaptes à la culture du maïs et juste bons à la culture arachidière, une culture peu exigeante. Des années ont passé et les agriculteurs continuent à produire du maïs. Cette production est conditionnée par l'utilisation des engrais minéraux permise par la culture du coton. Introduire des légumineuses permettrait d'améliorer la fertilité du sol par effet direct de l'arbre et par l'utilisation des émondes dans la fabrication de la fumure organique ou pour couvrir les sols cultivés (Salama et al., 2016).

L'objectif principal est d'expérimenter les principes de l'Agriculture de Conservation dans une région où les surfaces cultivées sont limitantes. Il s'agit, spécifiquement d'expérimenter un changement qui a permis le maintien du maïs dans les assolements par le recyclage des résidus de culture, dont le principe est basé sur l'alternance maïs/légumineuses. Aussi, diverses composantes (rendement et mesure de la performance à travers la surface relative nécessaire en cultures pures ou LER (Land Equivalent Ratio)) de l'association maïs-légumineuse au niveau des arrangements spatiaux ont-elles été comparées.

\section{Matériel et méthode}

\subsection{Site d'étude}

Le site d'étude est une ferme agricole d'environ 7 ha, exploitée par la coopérative agricole de Kafigué (095 $55^{\prime} 28.2^{\prime \prime} \mathrm{N}$ et 5³4'38 W), Korhogo (Nord de la Côte d'Ivoire). La description de profils sur le terrain et les résultats des analyses ont permis de rattacher ces profils à la classification internationale des sols (IUSS Working Group WRB 2014), dont les plus représentatifs sont les Cambisols en haut de versant et mi-versant et, des Gleysols dans les bas de versants. Au sein de cette zone d'étude, une parcelle permanente de 1 ha a été créé dont les sols sont très compacts, à texture sableuse ou sablo-argileuse dans les 20 premiers $\mathrm{cm}$. Une expérience sur le terrain y a été menée pendant les années 2015 - 2016 et 2016 - 2017 pour examiner l'effet de différentes stratégies de travail du sol (labour et billon) et de systèmes de culture (association maïs-légumineuse) sur les rendements du maïs. Le climat de la région de Korhogo est soudano-sahélien de type tropical de transition avec une saison des pluies (avril-octobre) et une saison sèche (Adja et al., 2009). La précipitation annuelle est de $1.350 \mathrm{~mm}$ (Brou, 2009). 


\subsection{Conduite de l'essai agronomique}

L'essai a été conduit dans un bloc aléatoire complet randomisé (Bloc de Fischer), avec plan de traitement (Tableau I) à 4 répétitions. La parcelle de superficie totale $51 \mathrm{~m}$ x $34 \mathrm{~m}\left(1734 \mathrm{~m}^{2}\right)$ est subdivisée en quatre blocs séparés de $2 \mathrm{~m}$ et 8 sous blocs séparés (sous bloc labour à plat et sous bloc billon alterné) de $1 \mathrm{~m}$ puis en 56 parcelles élémentaires de $20 \mathrm{~m}^{2}$ séparées entre elles de $1 \mathrm{~m}$. Ainsi, Cajanus cajan « cajanus » associé au maïs et à l'arachide en relais ont été installés au cours de la campagne agricole de la première année d'étude sur billon et labour à plat. Un écartement de $0,80 \mathrm{~m} \times 0,5 \mathrm{~m}$ est utilisé entre les pieds de maïs en alternance avec le cajanus. L'arachide est semée entre les lignes de maïs avec un écartement de 0,4 x 0,30 et séparé des pieds de cajanus ou de maïs de $20 \mathrm{~cm}$, soit deux (2) lignes d'arachide entre les pieds de maïs et de Cajanus cajan lorsque l'arachide leur est associée. Les trois cultures ont été semées le même jour. Après la récolte des cultures associées, le cajanus a poursuivi son développement jusqu'en début de la campagne suivante, soit 11 mois de développement végétatif alors que les résidus de maïs et de l'arachide sont restés sur place dans les différents traitements après la récolte. Au cours de la campagne agricole de la deuxième année, aucune activité de labour n'a été effectuée. Les blocs anciennement labouré ou billonné ont été conservés.

$\mathrm{T} 0=$ maïs en culture pure ;

$\mathrm{T} 1=$ cajanus en culture pure ;

$\mathrm{T} 2=$ arachide en culture pure ;

$\mathrm{T} 3$ = maïs associé à cajanus semé sur toutes les lignes de maïs entre les poquets ;

T5= cajanus associé à l'arachide ;

T4 = maïs associé à l'arachide semée entre les poquets de maïs en sautant chaque fois une ligne de maïs ;

T6 = maïs associé à cajanus+ arachide semée entre les poquets de maïs en sautant chaque fois une ligne de maïs.

Aucun engrais a été apporté aussi bien sur le traitement témoin (T0) que pour les autres traitements. Le matériel d'essai agronomique est constitué de semences $\left(25 \mathrm{~kg}\right.$. ha $\left.{ }^{-1}\right)$ de variétés locales (tolérantes à la sécheresse) d'arachide, de maïs de variété locale et de cajanus. Pour éviter la concurrence des mauvaises herbes et maintenir la culture exempte d'insectes, de ravageurs et de maladies, les mesures de protection des plantes ont été appliquées de manière uniforme.

\subsection{Observations et mesures}

\subsubsection{Rendement en grain}

Les rendements en grains ont été évalués en décembre 2016 et 2017 à maturité après la récolte sur une superficie de 39,2 $\mathrm{m}^{2}$ (7 m x 5,6 m). Les lignes 
de bordure n'ont pas été récoltées. Après le tri des épis et gousses pourris et d'autres déchets, il a été procédé à la pesée. Le rendement (Rdt) se calcule selon la formule utilisée par Maliki et al. (2020) :

$$
\text { Rdt }=\text { PF } \times \frac{100-\mathrm{Te}}{100} \times \frac{1000}{\mathrm{~S}} \times \frac{1}{1000}
$$

Où $\mathrm{Rdt}=$ rendement céréalier $\left.\left(\mathrm{kg} \mathrm{ha}^{-1}\right)\right) ; \mathrm{PF}=$ Poids frais des graines par surface élémentaire $(\mathrm{kg}) ; \mathrm{S}=$ Surface élémentaire $; \mathrm{TE}=$ Teneur en eau des graines, par la méthode de l'humidimètre de marque Pfeuffer He 50).

\subsubsection{Land Equivalent Ratio (LER)}

Le Land Equivalent Ratio (LER) est défini par Willey et Osiru (1972) et représente la surface de terre qui serait nécessaire en cultures pures pour obtenir les mêmes rendements qu'en culture associée. Le LER est déterminé selon la formule utilisée par Baldé (2011) et Doubi et al. (2016).

$$
\text { LER }=\frac{\text { Rendement espèce } A}{\text { Rendement espèce } A \text { en cultur pure }}+\frac{\text { Rendement espèce } B}{\text { Rendement espèce } B \text { en cultur pure }}=\mathrm{LA}+\mathrm{LB}
$$

Où LA et LB sont les rendements relatifs de chaque espèce; le LER est également appelé rendement relatif total selon Doubi et al. (2016)ou également rapport équivalent terre (RET).

Si LER $=1$, il n'y a aucune différence entre les deux modes de culture

Si LER $<1$, il y a une perte de rendement en association

Si LER >1, il y a un avantage productif des associations.

\subsection{Analyse des données}

Une analyse de variance (ANOVA) à trois facteurs a été menée pour déterminer les effets du système de culture, de l'année de culture et du traitement sur les rendements en grains de maïs. L'analyse des résidus a été effectuée pour vérifier les hypothèses de l'ANOVA. La normalité a été évaluée à l'aide du test de Shapiro-Wilk et l'homogénéité des variances a été évaluée par le test de Levène. Les résidus étaient normalement distribués ( $\mathrm{p}$ > $0,05)$ et les variances étaient homogènes $(p>0,05)$. Des tests de comparaison multiples ont été effectués entre les traitements, pour détecter des différences significatives grâce au logiciel R 4.0.3 ( $\mathrm{R}$ Core Team, 2019) et de l'environnement RStudio (RStudio Team, 2018).

\section{Résultats et discussion}

\subsection{Effets principaux des traitements des essais d'amélioration maïs- légumineuse sur billon}

Le traitement statistique sous forme factorielle sur billon (Tableau I) montre que l'arrangement spatial a eu des effets significatifs sur le rendement du maïs, de cajanus et de l'arachide. Le rendement du maïs pur est significativement supérieur à celui du maïs en culture mixte $(-17 \%$ en T3, $57 \%$ en $\mathrm{T} 4$ et $-33 \%$ en $\mathrm{T} 6$ ). Le traitement $\mathrm{T} 3$ semble favoriser le maïs aux 
dépens du cajanus et de l'arachide par rapport au traitement $\mathrm{T} 4(+48 \% \mathrm{du}$ rendement maïs, $-38 \%$ du rendement cajanus et $-15 \%$ du rendement arachide). L'interférence T3/T6 indique que T3 semble favoriser le maïs et le cajanus aux dépens de l'arachide par rapport à T6 $(+19 \%$ du rendement maïs, $+9 \%$ du rendement cajanus et $-27 \%$ du rendement arachide). Quant à l'interférence T4/T6, elle montre que la culture intercalaire (T4) favorise le cajanus aux dépens du maïs et de l'arachide par rapport à T6 (+34\% du rendement cajanus, $-55 \%$ du rendement maïs et $-10 \%$ du rendement arachide). Il ressort que le cajanus se montre plus productif $(+34 \%)$ en culture associée avec l'arachide sur billon.

Tableau I : Rendements en cultures pure et associée de Maïs, Cajanus et Arachide sur billon.

\begin{tabular}{llll}
\hline & \multicolumn{3}{c}{ Rendement sur billon $\left(\mathrm{kg}^{-h^{-1}}\right)$} \\
\hline Systèmes culturaux & Maïs & Cajanus & Arachide \\
\hline Maïs pur (T0) & $1141^{\mathrm{a}}$ & - & - \\
Cajanus pur (T1) & - & $442^{\mathrm{a}}$ & - \\
Arachide pure (T2) & - & - & $476^{\mathrm{a}}$ \\
Association maïs + cajanus [culture mixte 1] (T3) & $946^{\mathrm{b}}$ & $255^{\mathrm{c}}$ & $265^{\mathrm{c}}$ \\
Association maïs + arachide [culture mixte 2] (T4) & $492^{\mathrm{d}}$ & $353^{\mathrm{b}}$ & $305^{\mathrm{bc}}$ \\
Association maïs + cajanus + arachide [culture mixte 3] (T6) & $765^{\mathrm{c}}$ & $233^{\mathrm{c}}$ & $337^{\mathrm{b}}$ \\
\hline Signification stat. & $\mathrm{s}$ & $\mathrm{s}$ & $\mathrm{s}$ \\
CV (\%) & $10,03 \%$ & $11,04 \%$ & $11,68 \%$ \\
\hline
\end{tabular}

Les chiffres affectés d'une même lettre ne diffèrent pas significativement au seuil de probabilité $\mathrm{P}=0,05$ (test Newman et Keuls) ; $\mathrm{S}=$ significatif

\subsection{Amélioration de la productivité maïs-légumineuse sur labour}

Le rendement des cultures pures est significativement supérieur à celui des cultures associées (Tableau II). Par exemple, le maïs en culture pure est significativement supérieur à celui du maïs en culture associée (- 56\%, - 69\% et $-47 \%$, en T3, T4 et T6, respectivement). Le traitement T3 semble favoriser fortement le maïs et le cajanus aux dépens de l'arachide, par rapport au traitement $\mathrm{T} 4(+30 \%$ du rendement maïs, $+63 \%$ du rendement cajanus et $-4 \%$ du rendement arachide). L'interférence T3/T6 indique que la culture sous T3 semble favoriser l'arachide et le cajanus aux dépens du maïs, par rapport à T6 ( $-22 \%$ du rendement maïs, $+38 \%$ du rendement cajanus et $+11 \%$ du rendement arachide). T4 favorise faiblement l'arachide aux dépens du maïs et du cajanus, par rapport à $\mathrm{T} 6(-73 \%$ du rendement maïs, $-66 \%$ du rendement cajanus et $+14 \%$ du rendement arachide). Il ressort que sur sol labouré, l'arachide se montre plus productive $(+14 \%)$ en culture associée avec le cajanus.

Tableau II : Rendements en cultures pure et associée de Maïs, Cajanus et Arachide sur labour. 


\begin{tabular}{|c|c|c|c|}
\hline & \multicolumn{3}{|c|}{ Rendement sur labour $\left(\mathrm{kg} \cdot \mathrm{ha}^{-1}\right)$} \\
\hline Systèmes culturaux & Maïs & Cajanus & Arachide \\
\hline Maïs pur (T0) & $1199^{\mathrm{a}}$ & - & - \\
\hline Cajanus pur (T1) & - & $1269^{\mathrm{a}}$ & - \\
\hline Arachide pure (T2) & - & - & $439^{\mathrm{a}}$ \\
\hline Association maïs + cajanus (culture mixte 1 (T3) & $527^{\mathrm{c}}$ & $995^{\mathrm{b}}$ & $324^{\mathrm{b}}$ \\
\hline Association maïs + arachide (culture intercalaire (T4) & $370^{\mathrm{d}}$ & $370^{\mathrm{d}}$ & $338^{\mathrm{b}}$ \\
\hline Association maïs + cajanus + arachide (culture mixte 3 (T6) & $641^{\mathrm{b}}$ & $616^{\mathrm{c}}$ & $289^{\mathrm{b}}$ \\
\hline Signification stat. & $\mathrm{S}$ & $\mathrm{s}$ & $\mathrm{S}$ \\
\hline $\mathrm{CV}(\%)$ & $10,83 \%$ & $6,04 \%$ & $14,8 \%$ \\
\hline
\end{tabular}

Les chiffres affectés d'une même lettre ne diffèrent pas significativement au seuil de probabilité $\mathrm{P}=0,05$ (test Newman et Keuls) ; $\mathrm{S}=$ significatif

\subsection{LER des essais d'amélioration maïs-légumineuse}

Les LER de ces traitements, d'après les tests de Friedman et Kramer, sont significativement supérieurs à 1 (LER cultures pures, avec 1,87, 1,91 et 1,97). Ce qui signifierait que les cultures mixtes ont produit un gain de rendement variant entre $87 \%$ et $97 \%$, soit un écart de $10 \%$ par rapport aux cultures pures. La productivité globale de l'association par rapport aux cultures pures a fait apparaître un surrendement des trois systèmes de culture mixte sur le pur (LER > 1). Les cultures mixtes se sont donc montrées plus productives que la culture pure. Ces résultats ont indiqué que les LER ont représenté un indice d'efficacité biologique d'utilisation de la terre par les cultures associées sur le site d'étude soumis à une pression foncière forte (la terre est limitante). Une analyse de variance à trois facteurs a montré qu'il n'y avait pas une interaction statistiquement significative entre le système type de travail de sol, l'année et les traitements. Ces résultats traduisent statistiquement qu'il n'ya pas de perte de rendement au cours du temps quel que soit le type du travail du sol (labour à plat ou billon) par rapport témoin et aux trois (3) cultures avec association, $\mathrm{F}(3,24)=0,24, \mathrm{p}=0,87$ (Figure 1). De ce fait, les paysans n'ont aucune crainte à cultiver sur labour à plat comme sur billon. 


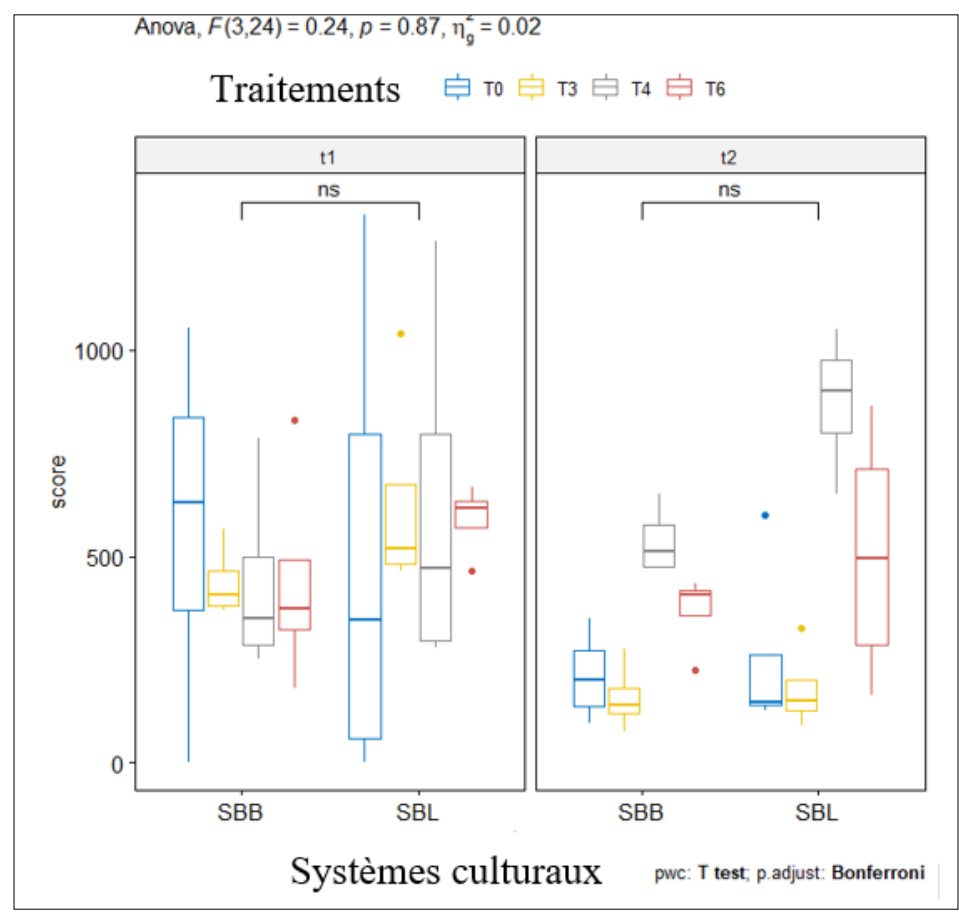

Figure 1. Stratification de rendement du maïs dans le cadre des différentes stratégies de cultures associées

\subsection{Effet des systèmes de cultures sur l'utilisation efficiente du terrain}

Les résultats ont indiqué que les LER sont significativement supérieurs à 1 , avec $1,87,1,91$ et 1,97 (sur labour), 1,37, 1,81 et 1,97 (sur billon); ce qui signifierait que les cultures mixtes ont produit un gain de rendement variant entre $87 \%$ et $97 \%$, soit un écart de $10 \%$ par rapport à la culture sur labour et une fourchette de $60 \%$ en billon. La productivité globale de l'association par rapport aux cultures pures, a fait apparaître un surrendement des trois systèmes de culture mixte sur le pur (LER > 1).

Tableau III : LER en cultures pure et mixte de maïs, cajanus et arachide sous billon et labour.

\begin{tabular}{lcllll}
\hline \multirow{6}{*}{ Labour } & $\begin{array}{l}\text { Systèmes } \\
\text { culturaux }\end{array}$ & $\begin{array}{l}\text { Rendement } \\
\text { relatif mais }\end{array}$ & $\begin{array}{l}\text { Rendement relatif } \\
\text { Cajanus }\end{array}$ & $\begin{array}{l}\text { Rendement relatif } \\
\text { arachide }\end{array}$ & LER \\
& $\mathrm{T} 0$ & 1 & 0 & 0 & 1 \\
& $\mathrm{~T} 1$ & 0 & 1 & 0 & 1 \\
& $\mathrm{~T} 2$ & 0 & 0 & 1 & 1 \\
& $\mathrm{~T} 3$ & 0,83 & 0,58 & 0,56 & 1,97 \\
& $\mathrm{~T} 4$ & 0,43 & 0,80 & 0,64 & 1,87 \\
& $\mathrm{~T} 6$ & 0,67 & 0,53 & 0,71 & 1,91 \\
\hline \multirow{6}{*}{ Billon } & $\mathrm{T} 0$ & 1 & 0 & 0 & 1 \\
& $\mathrm{~T} 1$ & 0 & 1 & 0 & 1 \\
& $\mathrm{~T} 2$ & 0 & 0 & 1 & 1,96 \\
& $\mathrm{~T} 3$ & 0,44 & 0,78 & 0,74 & 1,37 \\
& $\mathrm{~T} 4$ & 0,31 & 0,29 & 0,77 & 1,68 \\
\hline
\end{tabular}


La figure 2 révèle les valeurs moyennes totales LER des trois systèmes associations installés sur labour et billon. L'analyse de variance révèle une différence significative entre les valeurs LER des différentes associations culturales $(p<0,05)$. Il ressort de cette figure que toutes les associations culturales présentent un avantage en termes d'utilisation du terrain par rapport à la culture pure, quel que soit le type du travail du sol (LER >1). Ces avantages se situent aussi bien au niveau de l'utilisation efficiente du terrain qu'au niveau du gain en termes de production globale du système. En outre, les sols labourés présentent plus d'avantage en termes d'utilisation efficiente du terrain que les sols billonnés. Il ressort de cette figure que les systèmes d'associations cajanus-maïs et cajanus-maïs-arachide présentent les meilleurs avantages en termes d'utilisation du terrain aussi bien au niveau des sols labourés que des sols billonnés.

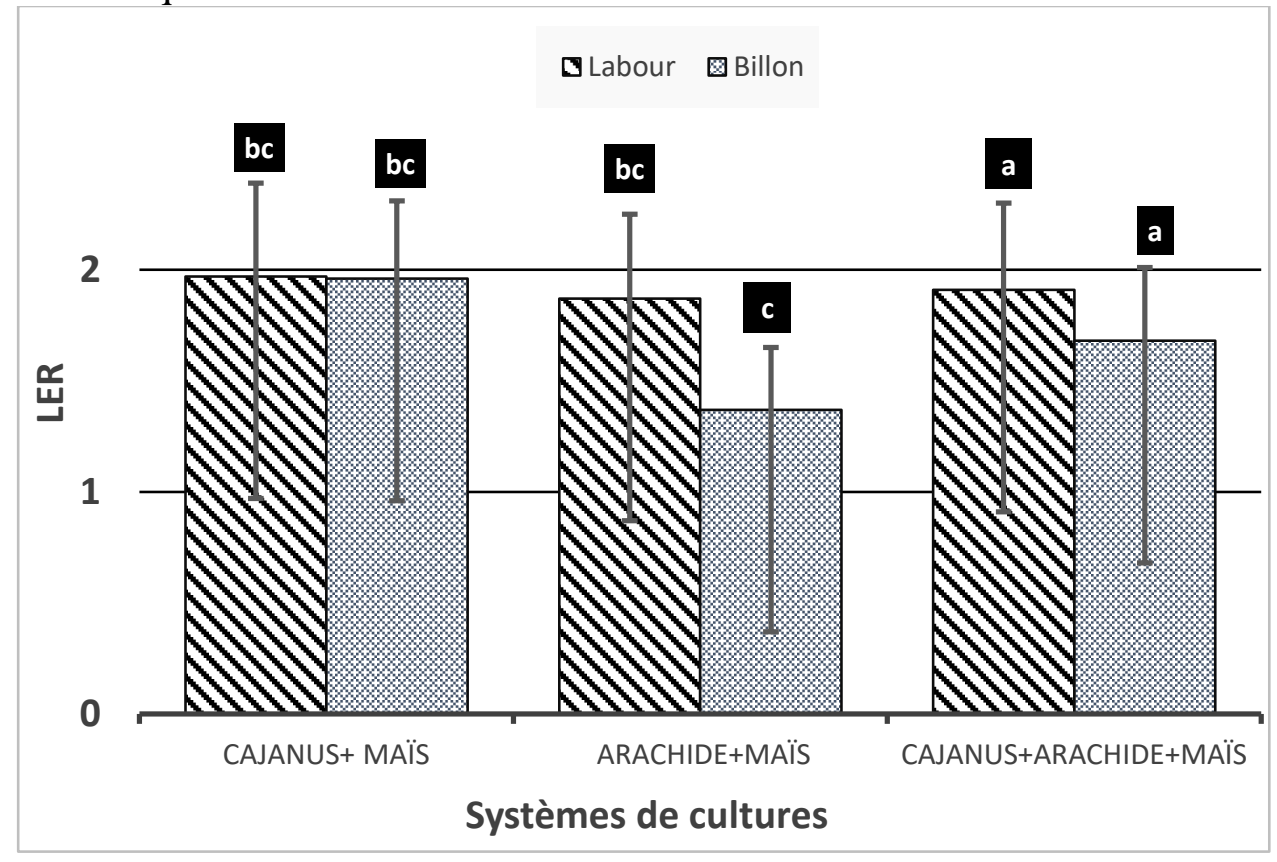

Figure 2 : LER (Land Equivalent ratio) des associations maïs-légumineuses

\section{Discussion}

Les analyses des données ont montré une différence significative entre le rendement des systèmes culturaux. Le rendement du maïs associé est significativement inférieur à celui du maïs pur (sur labour, - 56\%, - 69\% et $47 \%$, en T3, T4 et T6, respectivement et sur billon, - $17 \%$ en T3, - $57 \%$ en T4 et -33\% en T6) ; Chui et Nadar (1984) rapportent une baisse de rendement du maïs en culture mixte de $15 \%$, par rapport à la culture pure. Ce résultat est comparable au notre qui reste plus marqué, avec $-56 \%$ et $-17 \%$ de rendement pour le maïs et $-47 \%$ et $-33 \%$ pour le cajanus en culture mixte (T3 et T6) sur 
labour et billon, respectivement. Azontondé (1993) a attribué la baisse de rendement en grains de maïs associé avec une autre légumineuse (mucuna) à la réduction des densités de semis. Des résultats similaires ont été obtenus par (Coulibaly et al. 2017) dans le cas d'une étude semblable. En effet Coulibaly et al. (2017) ont comparé le rendement grain maïs obtenus en monoculture à ceux obtenus en association avec mucuna et le niébé. Ainsi, ces auteurs ont pu observer que le rendement en grain de maïs en culture pure de maïs était statiquement supérieur à celui obtenu sous association avec les légumineuses. Ces résultats s'expliquent par la densité relativement plus importante de maïs qui est relativement plus importante en monoculture qu'en culture associée. L'on peut attribuer ces différences à l'effet de compétition qu'il y a en début de cycle entre légumineuses et le maïs pour l'utilisation de l'azote minérale du sol surtout que les sols de la zone d'étude sont relativement pauvres en azote. $\mathrm{Vu}$ que la légumineuse et la céréale associées sont toutes des espèces productrices de graines, cette association peut conduire à la diminution du phosphore ou à une compétition pour la nutrition azotée. Ces observations ont été très couramment rapportées par Christianson et Vleck (1991) ; CorreHellou (2005).

Dans les trois systèmes d'associations utilisés, le faible rendement de maïs obtenu pourrait s'expliquer par les densités de semis utilisées présents de l'association. En effet, l'arachide comme le cajanus ont produit plus de biomasse arienne sur les traitements arachide-maïs et Cajanus-maïs. Cette observation se traduit par la compétition entre les légumineuses et le maïs sur les facteurs essentiels de développement et croissance tels que la température et l'intensité d'éclairement. Coulibaly et al. (2012) ont montré que l'association légumineuse-maïs entraine une baisse de rendement de maïs par rapport à sa culture pure, mais de façon non significative. Ces différences peuvent s'expliquer par le décalage de semis entre le maïs et les légumineuses qui ont réduit le degré de compétition pour les ressources du sol entre les composants de l'association. Selon Barro (2014), les fortes densités de niébé associées au maïs influencent négativement le rendement grain de maïs. Cette performance des associations pourrait aussi s'expliquer par le fait que des différences phénologiques entre espèces peuvent leur permettre d'utiliser les ressources à des périodes différentes (Ofori et Stern, 1987). Ce phénomène peut s'expliquer par une concurrence supérieure due aux interférences plus fortes entre espèces et les légumineuses, aussi bien en culture mixte (T3 et T6) et qu'en culture intercalaire (T6). En culture intercalaire, en raison de l'hétérogénéité spatiale du couvert végétal, l'énergie lumineuse est avant tout disponible pour l'espèce dominante et l'arachide n'a pas pleinement bénéficié du rayonnement vertical, rejoignant en cela Cenpukdee et Fukai (1992).

Les valeurs du Taux de Surface Equivalente (LER) total pour les trois systèmes d'associations sont supérieures à l'unité. Elles varient de 1,87 à 1,97 
dans l'essai billon et 1,37 à 1,97 dans l'essai labour à plat. Des résultats similaires ont été observés par Doubi et al. (2016) dans le cas d'association manihot esculanta et Lagenaria siceraria. Ces résultats signifient que l'association surpasse en rendement la culture pure respectivement de $87 \%$ et $97 \%$ en billon alors que l'association en labour surpasse en rendement la culture pure de $37 \%$ à $97 \%$. Les différentes associations culturales sont avantageuses par rapport à la culture pure, rejoignant en cela (Salez, 1988 ; Youri, 1998 ; Muoneke et al., 2007). Cela peut s'expliquer par une utilisation plus efficiente des ressources du milieu dans les associations que dans les cultures pures. En dépit de différence significative entre la culture sur billon et en labour, le meilleur système d'association du maïs et des légumineuses est l'association sur billon (surrendement moyen de $92 \%$ contre $67 \%$ en labour) ; N'Goran et N'Guessan (1999) ont rapporté également une amélioration du rendement en culture associé maïs-arachide de $18 \%$ le maïs. Par ailleurs, Ghanbari et al. (2010) ont rapporté que le maïs en association avec une légumineuse tel que le niébé augmente l'interception de la lumière, baisse l'évaporation de l'eau et améliore la conservation de l'humidité du sol en comparaison avec la culture pure du maïs. Le LER total supérieur à 1,37 observé avec le système d'association donne un avantage de l'association par rapport à la culture pure et demeure un atout pour une diffusion de cette technique.

\section{Conclusion}

À la lumière des essais, il apparaît que l'arrangement spatial a significativement eu un effet sur la production globale de celle-ci. Les LER ont indiqué une amélioration des cultures en association dans les deux types de travail du sol au cours de l'essai. Les différences d'écarts observés entre les LER sur billon et sur labour semblent favoriser fortement l'association maïslégumineuse sur Labour, par rapport à celle entreprise sur Billon. Les légumineuses, en revanche, se montrent moins productives en association culturale, du fait d'une concurrence plus forte du maïs, l'imbrication des plantes étant plus importante. En première approximation, la culture associée rationalisée offre davantage d'intérêt par rapport à la culture pure. Le LER total supérieur à 1,4 observé sous association, donne un avantage à cette approche culturale par rapport à la culture pure, et demeure un atout pour une diffusion de cette technique. Les différent LER totaux calculés montrent également une différence non significative entre les rendements obtenus sur Labour à plat et billons dans toutes les différentes associations légumineuses-maïs pour un système considéré. De ce fait les paysans n'ont aucune crainte à cultivé sur le labour à plat pour éviter de créer des poches à l'érosion à travers des sillons créer par le billonnage et qui se transforment en rigoles. Les systèmes d'associations Cajanus - maïs et cajanus-maïs-arachide présentent plus 
d'avantages en termes d'utilisation du terrain aussi bien au niveau des sols labourés que des sols billonnés.

\section{References:}

1. Adja, M. G., J. P. Jourda, Y. T. M., K. Koffi, K. J. Kouame, K. F. Kouame, M. B. Saley, K. B. Dje, and J. Biemi. 2009. Diagnostica la mi-saison sèche de l'état hydrique du bassin versant de la Bagoué ' (milieu soudano-sahélien de Côte-dメIvoire) a 1メaide dximages ETM +de Landsat. Sécheresse 20 :253-261.

2. Akotto, P., Boccanfuso, D. et Yergeau, M. (2020). L'agriculture urbaine et périurbaine, la pauvreté, la sécurité alimentaire et l'environnement dans les pays en développement : une revue exploratoire des méthodologies et des impacts. Document de travail du GRÉDI 20-03.

3. Azontondé A., 1993. Dégradation et restauration des terres de barre (sols ferralitiques faiblement désaturés argilo-sableux) au Bénin. Cahiers ORS TOM. Série Pédologie. 28 : 217- 226.

4. Baldé, A. B. 2011. Analyse intégrée du partage des ressources (eau, azote et rayonnement) et des performances dans les systèmes de culture en relais sous semis direct en zone tropicale subhumide. Thèse $161 \mathrm{p}$.

5. Barro A., 2014. Effets de la densité et du décalage de la date de semis du niébé (Vigna unguiculata L. walp) sur les performances agronomiques et économiques de l'association maïs (Zea mays L) /niébé en situation réelle de culture dans les villages de Koumbia de Gombêlêdougou. Diplôme de master en production végétale à l'université polytechnique de Bobo-Dioulasso, Burkina Faso, 73p.

6. Bedoussac L. ; Triboulet P., Magrini M-B ; Rambault G.; Foissy D., Corre-Hellou G., 2013. Conséquences de l'introduction des cultures associées céréale-légumineuse à graines dans les filières. Analyse du point de vue des agriculteurs et des coopératives. Innovations Agronomiques $\mathrm{n}^{\circ} 32$, pp.199-212.

7. Brou, Y. T. 2009. Impacts des modifications bioclimatiques et de l'amenuisement des terres forestières dans les paysanneries ivoiriennes : quelles solutions pour une agriculture durable en côte d'Ivoire. Cuadernos Geográficos 45:13-29.

8. Cenpukdee, U. \& Fukai, S. 1992 Cassava/legume intercropping with contrasting cassava cultivars. 2. Selection criteria for cassava genotypes in intercropping with two contrasting legume crops Field Crops Res. 29135149.

9. Christianson, C. B. \& Vleck, P. L. G. (1991). Alleviating soil fertility constraints to food production in West Africa : Efficiency of nitrogen 
applied to food crops. In : Uzo Mokwunye, Eds. Alleviating soil fertility constraints to improve crop production in West Africa. Kluwer Academic Publishers, Dordrecht. pp. 45-57.

10. Chui J.A.N., Nadar H.M., 1984. - Effect of spatial arrangements on the yield and other agronomic characters of maize a $\mathrm{n} d$ legume intercrops. East Afric. Agric. and Forest J., 44 : 137-146.

11. Corre-Hellou, G. 2005. Acquisition de l'azote dans des associations pois-orge (Pisum sativum L. - Hordeum vulgare $L$.) en relation avec le fonctionnement du peuplement. Thèse de doctorat en sciences agronomiques de l'école doctorale d'Angers 211p.

12. Coulibaly K., van E., Autfray P., Nacro H.B. et Sédogo M.P., 2012. Premiers résultats sur l'intensification écologique et démarche participative en zone cotonnière à l'Ouest du Burkina Faso. Agronomie Africaine 24 (2): 129-141.

13. Coulibaly, K., A. P. K. Gomgnimbou, and M. Traoré. 2017. Effets des associations maïs-légumineuses sur le rendement du maïs (Zea mays L.) et la fertilité d'un sol ferrugineux tropical à l'ouest du Burkina Faso. Afrique SCIENCE $13: 226$ - 235.

14. De Wit C.T., Van Den Bergh J.P., 1965. - Competition between herbage plants. Neth. J. Agric. Sci., 13: 212-221.

15. Doubi, B. T. S., K. I. Kouassi, K. L. Kouakou, K. K. Koffi, J.-P. Baudoin, and B. I. A. Zoro. 2016. Existing competitive indices in the intercropping system of Manihot esculenta Crantz and Lagenaria siceraria (Molina) Standley. Journal of Plant Interactions 11:178-185.

16. Feller C., 1994. La matière organique dans les sols tropicaux à argile $1: 1$. Recherche de compartiments organiques fonctionnels. Une approche granulométrique. Thèse de doctorat d'Etat, université LouisPasteur, Strasbourg, France, 393 p. + annexes.

17. Feller C., 1995. La matière organique du sol et la recherche d'indicateurs de la durabilité des systèmes de culture dans les régions tropicales semi-arides et subhumides d'Afrique de l'Ouest. In Sustainable land management in African semi-arid et subhumid regions. Proceedings of the SCOPE workshop, 15-19 Novembre 1993, Dakar, Sénégal. CIRAD-CA, Montpellier, France, p. 123-130.

18. Ghanbari A., Dahmardeh M., Siahsar B.A. et Ramroudi M., 2010. Effect ofmaize (Zea mays L.) cowpea (Vigna unguiculata L.) intercropping on light distribution, soi) temperature and soil moisture in and environment. Journal of Food Agriculture and Environment8: 102- 108

19. IUSS Working Group WRB. 2014. "World Reference Base for Soil Resources 2014. International soil classification system for naming soils and creating legends for soil maps." FAO, Rome. 
20. Koulibaly, B., O. Traoré, D. Dakuo, P. N. Zombré, and D. Bondé. 2010. Effets de la gestion des résidus de récolte sur les rendements et les bilans culturaux d'une rotation cotonnier-maïs-sorgho au Burkina Faso. Tropicultura $28: 184-189$.

21. Lal, R., D. C. Reicosky, and J. D. Hanson. 2007. Evolution of the plow over 10,000 years and the rationale for no-till farming. Soil and Tillage Research 93:1-12.

22. Maliki, R., Bello, S., N'Djolossè, K., Hinnou, L. C., Houénou, C. \& Dagbénonbakin, G. D. (2020). Performances agronomiques des variétés améliorées d'arachide introduites du Mali dans les conditions écologiques du Centre-Bénin. Journal of Animal \& Plant Sciences, 46(3), 8271-8287. https://doi.org/10.35759/JAnmPlSci.v46-3.1.

23. Muoneke C.O., Ogwuche M.A.O. et Kalu B.A., 2007. Effect of maize planting density on the performance of maize/soybean intercropping system in a Guinea savannah agroecosystem. African Journal of Agricultural Research 2(12): 667-677.

24. N'Goran A. et N'Guessan K.A., 1999. Influence d'un précédent de légumineuse herbacée et d'une jachère courte de deux ans sur la productivité du maïs au Nord de la Côte d'Ivoire. ln: Floret $\mathrm{C}$ et Pontanier $\mathrm{R}$ (Eds). La jachère en Afrique tropicale : rôles, aménagements, alternatives. Dakar (Sénégal): IRD; pp 616-621.

25. N'Guessan, K. A., K. E. Kouakou, K. A. Alui, and A. Yao-kouamé. 2019. Stratégies et pratiques paysannes de gestion durable de la fertilité des sols dans le département de Korhogo au Nord de la Côte d'Ivoire. Afrique SCIENCE $15: 245$ - 258.

26. Ofori, F. \& Stern, W. R. (1987). Cereal - Legume Intercropping Systems. Advanced Agronomy, 41, 41-90. https://doi.org/10.1016/S0065-2113(08)60802-0.

27. R Core Team : R. 2019. A Language and Environment for Statistical Computing, R Foundation for Statistical Computing, Vienna, Austria, available at: http://www.R-project.org, 2019.

28. RStudio Team: RStudio. 2018. Integrated Development Environment for R, RStudio, Inc., Lewis, J.; Freitas, F. Physical and Chemical Methods of Soil and Water Analysis; Food and Agriculture Organization (FAO): Rome, Italy, 1984; p. 275.

29. Salama, H.S.A. Zeid Hay, M.M.K. 2016. Quality evaluation of summer grass and legume forage monocultures and mixtures grown under irrigated conditions Aust. J. Crop. Sci., 11 (2016), p. 1543.

30. Salez P., 1988. Compréhension et amélioration des systèmes de cultures associées céréale-légumineuses au Cameroun. Thèse Doct. Ing. Insam. Nogent-sur-Marne, France, Cirad-irat, 190 p. 
31. Scopel, E., A. Findeling, E. C. Guerra, and M. Corbeels. 2005. Impact of direct sowing mulch-based cropping systems on soil carbon, soil erosion and maize yield. Agronomy for Sustainable Development 25:425-432.

32. Willey, R.W. Osiru, D.S.O. 1972. - Studies on mixtures of maize and beans (Pltaseolus wlgaris) with particular reference to plant population. J. Agric. Sci. Camb., 79 : 517-529.

33. Youri A., 1998. Système de culture avec légumineuses au Cameroun. In: Cover crops in West Africa; Contributing to sustainable agriculture. Ottawa, Canada, IDRC, p. 225-227. 